\title{
Factors Influencing the lead time of chicken transportation
}

\author{
Narjice El-ghardouf ${ }^{1^{*}}$, Ahmed Elakkary ${ }^{1}$, and Nacer Sefiani ${ }^{1}$ \\ ${ }^{1}$ Systems Analysis, Information Processing and Integrated Management Laboratory, Superior School of Technology of Salé, \\ Mohammed V University, Rabat, Morocco
}

\begin{abstract}
The paper's purpose is to analyze thirteen variables behind the inappropriate lead time of chicken transportation and determine the factors affecting this distribution. Data, using the snowball sampling method, included 264 questionnaires collected from chicken truck drivers. First, we use the principal component analysis (PCA) to identify the factors contributing to the longest delivery time. We find through PCA that all the variables analyzed take part significantly in the transport time. The most important factors were Connectivity, Resources, Verification \& Frisking, Road, and Planning. Improving these factors will optimize the lead time of transport, consequently; improving profitability and animal welfare and quality. The findings are useful to production companies of any fresh products looking to improve their delivery time and increase more benefits.
\end{abstract}

\section{Introduction}

According to the Moroccan agricultural ministry, the poultry sector is one of the most dynamic activities in the country, with an average growth rate during the last four decades of around $7.7 \%$ of poultry production, and $3.5 \%$ of egg production. In 2019 , the production of poultry meat was 625,000 tons, and 6.1 billion eggs for consumption, these products are consumed by the entire population.

Depending on the inter-professional federation of the poultry sector of Morocco (FISA), the marketing and transportation of chicken in Morocco have a lack of strict regulations that follow a primitive system. More than $85 \%$ of the chickens are sold alive by small retailers who buy either from the wholesale market or directly from farms depending on the region. The Moroccan consumer, therefore, prefers to buy the animal still alive and generally gives it to an adjacent slaughterhouse for the slaughtering service - plucking.

Meanwhile, the developed countries know a remarkable evolution in the last decades, in poultry transportation, such as the United States, Canada, and the European Union. Morocco still has various difficulties in this field. Indeed, the process of chicken transport from loading, transferring, to discharging to the final customer suffers from several constraints, e.g. inappropriate catching, over packaging, old truck, and poor transport conditions.

In fact, birds lived until their maturity in industrial or even traditional henhouses with invariable environmental conditions. Then they are suddenly exposed to different changes like being handled, caught, and withdrawal of food and water. They experience stimulators that may be new, such as motion with vibration, speed, noise as driving behavior, cancelling of food and water, bad weather conditions, lack of hygiene in cages [1-3], overcrowding, temperature extremes [4], long distance and duration of delivery [5].

The consequences of these factors can vary between physical, psychological injuries, behavioural changes, and even broilers mortality [6-7]. On the other hand, they contribute to fewer incomes to the stakeholders.

Many papers are focused to study the effect of these factors mentioned before on the animal welfare, quality and mortality during transportation. However, few researchers are conducted in the field of transportation lead time factors.

The aim of the survey is to identify variables behind inappropriate transportation lead time of poultry products concerning chicken, and factors associated with this process of distribution form farms to the wholesale markets. Such knowledge may be helpful to indicate measures to be taken to reduce the transportation lead time in the food supply chain. Therefore, the quality, cost, and delivery time of the product could be satisfactory.

\section{Data}

The study was conducted in Rabat, which is a Moroccan city where chicken's production and consumption are significant compared to the country, especially in the summer season. Up to now, there is no such research work available on poultry transportation in Morocco. For collecting the data used in the analysis, a survey with appropriate questions was essential.

According to the consultation with poultry experts, a questionnaire was drawn up using closed questions to obtain the desired quantifiable data. Participants should choose only one of the answers given on a 5-point Likert

* Corresponding author: narjice.elghardouf@gmail.com 
scale ranging from 1 (not significant) to 5 (very significant).

Then, the sample of interviewees was defined directly in the field. It was offered to people who are mainly related to chicken transport. They are responsible for the delivery of these perishable products to markets. As there is no list of transporters, the snowball sampling method was used to identify the respondents. This method usually starts with a few people who have the desired characteristics and use those people to identify others with the same ones [8].

The distributed questionnaire includes sociodemographic data such as age, educational level, experience in transportation, and the type of job held by the interviewer. From the selected state, Table 1 presents these characteristics expressed by percentage. It shows that the major age category of chicken transporters was between $35-49$ years, with a percentage of $56 \% ; 58 \%$ of the interviewers went to primary school, and only $22 \%$ of them were at secondary school. In terms of experience in transportation, only $4 \%$ of chicken transporters have more than 20 years of experience, $26 \%$ with experience between $15-20$ years, $42 \%$ for the 10 15 years' category, and $8 \%$ less than 5 years of experience. Regarding the nature of employment, $68 \%$ of the interviewers are individual external truck drivers, $26 \%$ are farm drivers, and only $6 \%$ are managers on registered farms or individual owners of their small farms. This is satisfied: truck drivers are the most concerned by this study since they are the most experienced in the field, and know the operational problems that transportation encounters.

The study focuses on a total of thirteen variables. They were the fruit of the investigation carried out.
Three hundred questionnaires were distributed, but only 264 participants completed all the questionnaire responses, with a response rate of $88 \%$. Therefore, the number is sufficient for factor analysis: a recommended sample size to variables ratio would be $20: 1$, which means 20 cases per variable [9]. The list of variables of chicken's transport that is covered in this paper is presented in Appendix A.

\section{Research methods}

\subsection{Principal Component Analysis}

To extract the reasons behind the inappropriate transportation time in the poultry supply chain regarding chicken; data analysis was performed using the principal component analysis method (PCA). It is used when the analysis is based on a large number of observed variables such as that of this study, and wish to reduce this number to a smaller one of variables, called "principal components" that will account for most of the variance of the variables without losing the information contained [10].

The objective of PCA is to reduce the information into a smaller set of components by examining the matrix of item correlations. When the intercorrelation is high, items are assumed to be measuring the same latent component [11].

In other words, this technique produces orthonormal eigenvectors and eigenvectors as well as a non-negative square root of eigenvalues called singular values. The diagonal singular values are ordered in descending order. The largest eigenvalue corresponding to the largest eigenvector is the first principal component. The first principal component explains most of the variance

Table 1. Socio-demographic data's characteristics of respondents.

\begin{tabular}{|c|c|c|c|c|}
\hline & \multicolumn{2}{|r|}{ Categories } & \multirow{2}{*}{$\begin{array}{c}\text { Percentage } \\
30 \%\end{array}$} & \multirow{2}{*}{$\begin{array}{c}\text { Total number } \\
79\end{array}$} \\
\hline \multirow{19}{*}{ 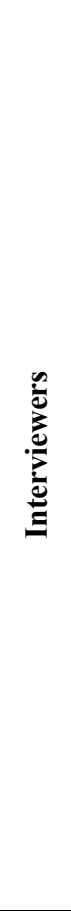 } & \multirow{4}{*}{ Age } & $20-34$ & & \\
\hline & & $35-49$ & $56 \%$ & 148 \\
\hline & & 50 and more & $14 \%$ & 37 \\
\hline & & Total & $100 \%$ & 264 \\
\hline & \multirow{5}{*}{ Education } & No education & $15 \%$ & 40 \\
\hline & & Primary school & $58 \%$ & 153 \\
\hline & & Secondary school & $22 \%$ & 58 \\
\hline & & University studies & $5 \%$ & 13 \\
\hline & & Total & $100 \%$ & 264 \\
\hline & \multirow{6}{*}{ Experience } & $0-5$ years & $8 \%$ & 21 \\
\hline & & $5-10$ years & $20 \%$ & 53 \\
\hline & & $10-15$ years & $42 \%$ & 111 \\
\hline & & $15-20$ years & $26 \%$ & 69 \\
\hline & & More than 20 years & $4 \%$ & 10 \\
\hline & & Total & $100 \%$ & 264 \\
\hline & \multirow{4}{*}{ Type of job } & Farm drivers & $26 \%$ & 68 \\
\hline & & Manager/ Owner & $6 \%$ & 16 \\
\hline & & Individual truck drivers & $68 \%$ & 180 \\
\hline & & Total & $100 \%$ & 264 \\
\hline
\end{tabular}


in the dataset. The second principal component and subsequent principal components follow the same order [12].

Let $A$ be a real $m \times n$ matrix where $m \geq n$ :

$$
A=U \sum V^{T}
$$

The matrix $U$ consists of orthonormal eigenvectors associated with the largest eigenvalue of $A A^{T}$, and the matrix $\mathrm{V}$ consists of the orthonormal eigenvectors of $A^{T} A$. The diagonal elements of $\sum$ are the non-negative square roots of the eigenvalues of $A^{T} A$, and they are called singular values. Where:

$$
\sum=\operatorname{diag}\left(\sigma_{1}, \cdots, \sigma_{n}\right) \text { and } \sigma_{1} \geq \sigma_{2} \geq \cdots \geq \sigma_{n}>0
$$

For more details, [12].

In this paper, we use IBM SPSS: Statistical Package for the Social Sciences - Version 26, and the statistical processing was performed using the varimax method. However, before initiating the principal component analysis, it is necessary to measure the reliability of the variables using the Pearson correlation to test whether the dataset has the appropriate correlations to contribute to the extraction of the factors [13].

For this test, we use Coefficient $\alpha$ that is a measure index of the internal consistency between the variables. It varies between 0 and 1 and is considered "acceptable" from 0.7 . The closer the alpha value is to 1 , the more homogeneous the set of elements [14]. The result is presented in Table 2. Next, we conduct the KaiserMeyer-Olkin criterion, which is a processor that determines the appropriate number of principal components to represent the variance and the correlation between the variables. The KMO index varies between 0 and 1 and is considered "acceptable" from 0.6 [15]. The result is presented in Table 3. For the last test, a Bartlett's test of Sphericity is performed to examine the correlation between the variables. If the correlation matrix "Eq. (2)" is not identical to the identity matrix, the factor analysis is appropriate to the dataset [13].The result is also presented in Table 3 .

Let a dataset that has $\mathrm{n}$ observations and, for each observation $i(i=1, \ldots, n)$ values corresponding to each one of the $\mathrm{k}$ metric variables $\mathrm{X}$. The correlation matrix $\rho$ is defined as follows.

$$
\begin{aligned}
\rho & =\left(\begin{array}{cccc}
1 & \rho_{12} & \cdots & \rho_{1 k} \\
\rho_{21} & 1 & \cdots & \rho_{2 k} \\
\vdots & \vdots & \ddots & \vdots \\
\rho_{k 1} & \rho_{k 2} & \cdots & 1
\end{array}\right) \\
\rho_{j j^{\prime}} & =\frac{\sum_{i=1}^{n}\left(X_{j i}-\overline{X_{J}}\right) \times\left(X_{j \prime}-\overline{X_{J^{\prime}}}\right)}{\sqrt{\sum_{i=1}^{n}\left(X_{j i}-\overline{X_{J}}\right)^{2}} \times \sqrt{\sum_{i=1}^{n}\left(X_{j \prime i}-\overline{X_{J \prime}}\right)^{2}}}
\end{aligned}
$$

Where $\overline{X_{j}}$ and $\overline{X_{\mathrm{J}}}$ represent the means of variables $X_{j}$ and $X_{j}$, respectively. For more, see [13].

\subsection{Determination of Principal Components}

There are too many procedures to determine the exact number of principal components representing the factors related to the chicken delivery time; the most commonly used is the eigenvalue-one criterion, also known as the Kaiser criterion. It is based on the selection of components with eigenvalues equal to or greater than one [15]. Components with eigenvalues less than one are considered insignificant and are not retained [10]. The result is presented in Table 4. For further analysis, a second test is used to confirm the results of the first criterion. It's the Scree test, which is a decreasing curve determining the significant factors through the identification of the breakpoint at which the scree begins, and retained only the components appearing before the break [16], (Figure 1).

\subsection{Varimax rotation method}

After extracting the principal components, the most popular rotation method, which is known as Varimax, was used. It is an orthogonal rotation; whose aim is to maximize the variance of the squared loadings of a factor (column) on all the variables (rows) in a factor matrix. The result of the method allows identifying each variable with a single factor (principal component) [17], (Table 5).

\section{Research results}

\subsection{Reliability analysis}

The principal component analysis assumes the set of variables to be homogeneous. We use Cronbach's Alpha (Coefficient $\alpha$ ) to examine the correlation of the data. According to the SPSS results (Table 2), the Cronbach alpha is 0.865 greater than 0.7 , so that the data set meets the homogeneity of these elements. Next, we find the $\mathrm{KMO}$ measure of the sampling adequacy value to be 0.76 . Since the value obtained is superior to 0.6 , The $\mathrm{KMO}$ test indicates the adequacy of the factor (Table 3). The Bartlett's test of Sphericity indicates that the correlation matrix is different from the identity one: the approximate Chi-Square value of 2801,26 and a p-value of 0 . This result confirms that the correlation between the variables is significantly different from an identity matrix (Table 3).

Table 2. Cronbach's Test.

\begin{tabular}{|c|c|c|}
\hline $\begin{array}{c}\text { Cronbach's } \\
\text { Alpha }\end{array}$ & $\begin{array}{c}\text { Cronbach's } \\
\text { Alpha Based on } \\
\text { Standardized } \\
\text { Items }\end{array}$ & $\begin{array}{c}\text { N of } \\
\text { Variables }\end{array}$ \\
\hline 0,865 & 0,872 & 13 \\
\hline
\end{tabular}

Table 3. KMO and Bartlett's test.

\begin{tabular}{|l|l|c|}
\hline \multicolumn{2}{|c|}{$\begin{array}{c}\text { Kaiser-Meyer-Olkin Measure of } \\
\text { Sampling Adequacy }\end{array}$} & 0,769 \\
\hline \multirow{2}{*}{$\begin{array}{l}\text { Bartlett's Test of } \\
\text { Sphericity }\end{array}$} & Approx. Chi-Square & 2801,26 \\
\cline { 2 - 3 } & Df. & 78 \\
\cline { 2 - 3 } & Sig. & 0,000 \\
\hline
\end{tabular}


The three indices are judged acceptable and indicate that the factor analysis is appropriate in this case, and support the relevance of the principal component analysis used in this study.

\subsection{Principal Component Analysis}

Depending on the result of the Kaiser criterion presented bellow (Table 4), the first five principal components have initial eigenvalues superior to one; meanwhile, the remaining components have eigenvalues less than one and considered insignificant. Therefore, there are five factors (principal components) affecting lead time in chicken transportation.

The scree plot shows several breaks from component 1 to 5 , then the large breakpoint appears after the fifth component, allowing the line to start flattening. The components which follow this breakpoint and which constitute a semi-straight line are assumed to be trivial and not significant, as shown in Figure 1.

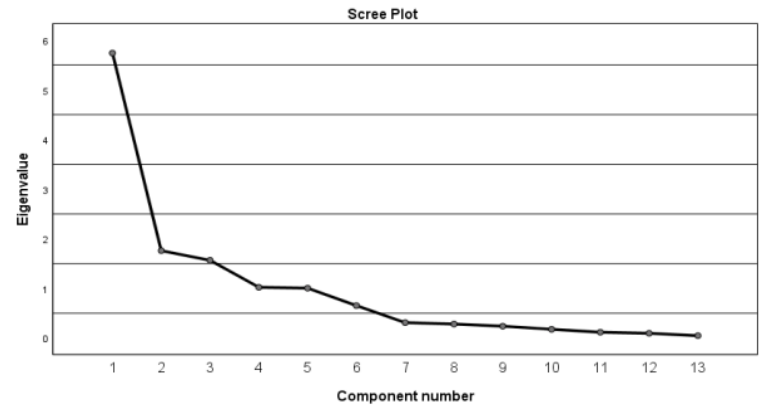

Fig. 1. Scree Plot.

The Kaiser criterion and the scree test are in agreement; there are five principal components (Factors) affecting transportation lead time in the chicken supply chain: they account for $85,3 \%$ of the variation across the sample. The PC1 to PC5 can be used to represent the 13 variables without losing the information contained.
After determining the exact number of principal components, the varimax method is used to link each variable with its factor and interpret the result of the study. The rotated matrix is presented in Table 5.

Table 5. Varimax Rotation Method.

\begin{tabular}{|c|c|c|c|c|c|}
\hline & \multicolumn{5}{|c|}{ Component } \\
\hline Variables & 1 & 2 & 3 & 4 & 5 \\
\hline $\mathrm{X}_{1}$ & 0,945 & - & - & - & - \\
\hline $\mathrm{X}_{2}$ & 0,836 & - & - & - & - \\
\hline $\mathrm{X}_{3}$ & 0,795 & - & - & - & - \\
\hline $\mathrm{X}_{4}$ & 0,695 & - & - & - & - \\
\hline $\mathrm{X}_{5}$ & 0,684 & - & - & - & - \\
\hline $\mathrm{X}_{6}$ & - & 0,761 & - & - & - \\
\hline $\mathrm{X}_{7}$ & - & 0,679 & - & - & - \\
\hline $\mathrm{X}_{8}$ & - & 0,676 & - & - & - \\
\hline $\mathrm{X}_{9}$ & - & - & 0,927 & - & - \\
\hline $\mathrm{X}_{10}$ & - & - & 0,778 & - & - \\
\hline $\mathrm{X}_{11}$ & - & - & - & 0,929 & - \\
\hline $\mathrm{X}_{12}$ & - & - & - & 0,807 & - \\
\hline $\mathrm{X}_{13}$ & - & - & - & - & 0,978 \\
\hline
\end{tabular}

By analysing the varimax-rotated component matrix of the PCA (Table 5), the loading plot of each variable allows us to clear up the correlations between the principal components and variables. First, we find that $X_{1}(0.945), X_{2}(0.836), X_{3}(0.795), X_{4}(0,695)$ and $X_{5}$ $(0,684)$ show high correlation with the first factor $(\mathrm{PC} 1$, with $31.056 \%$ of Variance); the variables $\mathrm{X}_{6}(0,761), \mathrm{X}_{7}$ $(0.679)$ and $\mathrm{X}_{8}(0,676)$ load to $\mathrm{PC} 2(17.475 \%$ of Variance); $X_{9}(0.927)$ and $X_{10}(0.778)$ are related to PC3 (14.614\% of Variance); $X_{11}(0.929)$ and $X_{12}(0.807)$ are correlated to PC4 (13.529\% of Variance); and finally,

Table 4. Kaiser Criterion.

\begin{tabular}{|c|c|c|c|c|c|c|}
\hline \multirow{2}{*}{ Component } & \multicolumn{3}{|c|}{ Initial Eigen values } & \multicolumn{3}{c|}{ Rotation Sums of Squared Loadings } \\
\cline { 2 - 7 } & Total & \% of variance & Cumulative \% & Total & \% of variance & Cumulative\% \\
\hline 1 & 5,740 & 44,156 & 44,156 & 4,037 & 31,056 & 31,056 \\
\hline 2 & 1,759 & 13,532 & 57,688 & 2,272 & 17,475 & 48,531 \\
\hline 3 & 1,565 & 12,040 & 69,728 & 1,900 & 14,614 & 63,145 \\
\hline 4 & 1,021 & 7,858 & 77,586 & 1,759 & 13,529 & 76,674 \\
\hline 5 & 1,004 & 7,725 & 85,311 & 1,123 & 8,637 & 85,311 \\
\hline 6 & 0,652 & 5,017 & 90,328 & & & \\
\hline 7 & 0,308 & 2,373 & 92,701 & & & \\
\hline 8 & 0,280 & 2,157 & 94,858 & & & \\
\hline 9 & 0,238 & 1,827 & 96,685 & & & \\
\hline 10 & 0,175 & 1,344 & 98,030 & & & \\
\hline 11 & 0,116 & 0,889 & 98,919 & & & \\
\hline 12 & 0,094 & 0,726 & 99,645 & & & \\
\hline 13 & 0,046 & 0,355 & 100,000 & & & \\
\hline
\end{tabular}


PC5 (8.637\% of Variance) has the last variable $\mathrm{X}_{13}$ (0.978). This is as shown in Table 6.

Table 6. Grouping factors with its corresponding variables.

\begin{tabular}{|c|c|c|c|}
\hline $\begin{array}{c}\text { Principal } \\
\text { Component }\end{array}$ & $\begin{array}{c}\text { Factor } \\
\text { Name }\end{array}$ & Weight & $\begin{array}{c}\text { Corresponding } \\
\text { Variables }\end{array}$ \\
\hline 1 & Connectivity & $\begin{array}{c}31,056 \\
\%\end{array}$ & $\begin{array}{c}\mathrm{X}_{1}, \mathrm{X}_{2}, \mathrm{X}_{3}, \mathrm{X}_{4} \\
\mathrm{X}_{5}\end{array}$ \\
\hline 2 & Resources & $\begin{array}{c}17,475 \\
\%\end{array}$ & $\mathrm{X}_{6}, \mathrm{X}_{7}, \mathrm{X}_{8}$ \\
\hline 3 & $\begin{array}{c}\text { Verification } \\
\& \text { Frisking }\end{array}$ & $\begin{array}{c}14,614 \\
\%\end{array}$ & $\mathrm{X}_{9}, \mathrm{X}_{10}$ \\
\hline 4 & Roads & $\begin{array}{c}13,529 \\
\%\end{array}$ & $\mathrm{X}_{11}, \mathrm{X}_{12}$ \\
\hline 5 & Planning & $\begin{array}{c}8,637 \\
\%\end{array}$ & $\mathrm{X}_{13}$ \\
\hline
\end{tabular}

The result can be interpreted that the lead time of chicken transportation may be affected by several factors. They are characterized by different rankings depending on the variance of each one.

\section{Discussion of the results}

The findings from this study show that several factors are affecting the delivery time of chicken transportation. The results imply that Morocco needs to handle these elements in orderly. According to the study, the first principal component, which loads bad road connectivity, bad driving condition, lack of communication between drivers, lack of organization structuring the field of chicken drivers, and longdistance between farm and wholesale, is the leading factor that can be called "Connectivity". It may be due to the unavailability of information. Indeed, the drivers are independents and have no structure framing them with no source of information that can allow them to plan the best route, best start, and even avoid poor road conditions (e.g. rain, accidents, traffic jams, dust storms...), despite the richness of the area and the proximity of the farms.

On the one hand, the various vehicles used by the drivers are generally old with a lifespan between 8 and 15 years, which increases the percentage of dysfunction, and breakdowns of these resources, therefore truck stops. On the other hand, the ignorance of the drivers about the fragility/time/quality of the product, and careless driving (speed, non-compliance with the road code, lack of sleep, fatigue...), are a significant reason reacting to the lead time. They constitute the second principal component that we named "Resources".

For the third factor, termed "Verification \& Frisking", the study shows that the truck drivers interviewed confirmed the continuous stops of their vehicles during the chicken delivery journey by the Moroccan police authorities. The police often order the stopping of these trucks to check the weight, the type of goods, the papers, the speed, and other criteria, which is why the lead time becomes very high compared to the distance travelled. The passage of the toll stations, which can encourage the delay, is little frequented.
The findings confirm that PC4 called "Roads" has less influence on lead time. In fact, the transport sector in Morocco has evolved a lot in recent years. According to the respondents of the questionnaire, the roads have become more and more suitable. Traffic jams are an important criterion. However, chicken truck drivers generally deliver overnight (between midnight and 4 a.m.), which avoid rush hours and allows a short delivery time.

In the end, the more well-planned and respected the departure time and duration, the more likely it is to have the availability of transport vehicles, better lead time, and better product quality when the destination arrives. These elements establish the last factor (PC5) named "Planning".

\section{Conclusion}

In conclusion, the road transport of chicken used in Morocco has evolved a lot in recent years. However, this model still has problems affecting the lead time during the delivery of these goods.

The principal component analysis was used to analyze the primary data collected from the drivers directly involved in the transportation of chickens and extract the principal components affecting the lead time. The PCA method yielded five principal components, with $85,311 \%$ of the total variance in the thirteen variables analyzed. The results show that all these variables contribute significantly to the delivery time of chicken transport.

By using the varimax method, the study defined five important factors behind inappropriate transportation lead time in the chicken supply chain: Connectivity, Resources, Verification \& Frisking, Roads, and Planning. Indeed, to improve lead time, it is necessary to act mainly on the first factors having the most significant impact on delivery. Hence the interest of future research.

This study is carried out in the Moroccan capital region. It can be performed in another area, on other food products, and confirm other factors using different methodologies.

\section{Appendix A}

\begin{tabular}{|l|l|}
\hline$X_{1}$ & Bad road connectivity \\
\hline$X_{2}$ & Poor driving conditions \\
\hline$X_{3}$ & Lack of communication between drivers \\
\hline$X_{4}$ & $\begin{array}{l}\text { lack of organization structuring the field of chicken } \\
\text { drivers }\end{array}$ \\
\hline$X_{5}$ & Long distance between farm and wholesale market \\
\hline$X_{6}$ & Unsuitable vehicles \\
\hline$X_{7}$ & Inappropriate driving behavior \\
\hline$X_{8}$ & $\begin{array}{l}\text { Not Awareness of the importance of time and quality } \\
\text { of transportation }\end{array}$ \\
\hline$X_{9}$ & Police verification and frisking \\
\hline$X_{10}$ & Frequent toll booths \\
\hline$X_{11}$ & Trafic James \\
\hline$X_{12}$ & Inappropriate route \\
\hline
\end{tabular}


$\mathrm{X}_{13}$ Poor departure planning and Non-punctual availability of transport vehicles

\section{References}

1. C. J. Nicol and G. B. Scott, Appl. Anim. Behav. Sci. 28, 1-2, pp. 57-73, (1990)

2. M. A. Mitchell and P. J. Kettlewell, Poult. Sci. 77, 12, pp. 1803-1814, (1998)

3. C. Hinojosa et al., Animals 8, 11, p. 195, (2018)

4. Weeks C.A, Poultry handling and transport, (Edt. Grandin Temple) pp. 378-398, (2004)

5. M. A. Mitchell and P. J. Kettlewell, World's Poult. Sci. J. 50, 1, pp. 57-59, (1994)

6. E. Voslarova, P. Chloupek, P. Vosmerova, J. Chloupek, I. Bedanova, and V. Vecerek, Poult. Sci. 90, 10, pp. 2144-2152, (2011)

7. E. Voslářová et al., Acta Vet. Brno. 76, 8, pp. 101108, (2007)

8. G. R. Sadler, H.-C. Lee, R. S.-H. Lim, and J. Fullerton, Nursi. \& Healt. Sci. 12, 3, pp. 369-374, (2010)

9. R. B. Kline, Principles and Practice of Structural Equation Modeling, (Edt Guilford Publications), (2015)

10. N. O'Rourke and L. Hatcher, A Step-by-Step Approach to Using SAS for Factor Analysis and Structural Equation Modeling, (2013)

11. A. P. Finch, J. E. Brazier, C. Mukuria, and J. B. Bjorner, Val. in Healt. 20, 10, pp. 1362-1375, (2017)

12. G. H. Golub and C. Reinsch, Numer. Math. 14, pp. 403-420, (1970)

13. L. P. Fávero and P. Belfiore, Data Sci. for Busi. and Deci. Mak., pp. 383-438 (Elsevier 2019)

14. L. J. Cronbach, Psychometrika 16, 3, pp. 297-334, (1951)

15. H. F. Kaiser, Educ. and Psych. Meas. 20, 1, pp. 141-151, (1960)

16. R. B. Cattell, Multiv. Beha. Res. 1, 2, pp. 245-276, (1966)

17. H. F. Kaiser, Psychometrika 23, 3, pp. 187-200, (1958) 